\title{
MANAJEMEN STRATEGI PADUAN SUARA DI SMA KRISTEN EBEN HAEZAR MANADO
}

\author{
${ }^{1}$ Serafim A. Harikusuma, ${ }^{2}$ Erwin Sianturi \\ ${ }^{1}$ Mahasiswa Pendidikan Musik Gereja IAKN Manado, ${ }^{2}$ Dosen Pendidikan Musik Gereja \\ IAKN Manado \\ 1'happysera.serafim@gmail.com ²esianturi@iakn-manado.ac.id
}

\begin{abstract}
Abstrak
Penelitian ini bertujuan untuk mendeskripsikan manajemen strategi paduan suara di SMA Kr. Eben Haezar Manado. Penelitian ini merupakan penelitian kualitatif dengan metode deskriptif. Lokasi penelitian di SMA Kr. Eben Haezar Manado, pada tahun 2019. Metode pengumpulan data dengan observasi, wawancara, dan dokumentasi. Dari hasil analisa dan interpretasi data, diperoleh indikasi bahwa: (1) Unsur-unsur manajemen strategi yang mendukung keberhasilan pengelolaan paduan suara ialah Man, Money, Method, Material,dan Market. (2) Manajemen strategi paduan suara di SMA Kr. Eben Haezar manado berjalan dengan baik. Proses perencanaan strategi dilakukan oleh para pengurus dengan arahan dan masukan dari pelatih dan guru Pembina, dan atas pengawasan dari pihak Yayasan Eben Haezar Manado. Dari hasil temuan tersebut, maka direkomendasikan untuk para pengurus Benzar Choir agar sebaiknya dapat membuat susunan organisasi secara tertulis supaya memudahkan dalam urusan arsip data Benzar Choir, serta menyusun susunan pengurus dengan menunjuk koordinator-koordinator agar dapat membantu menjalankan manajemen strategi yang telah direncanakan dengan lebih baik.
\end{abstract}

Kata kunci: Manajemen Strategi, Paduan Suara

\section{MANAGEMENT STRATEGY OF CHOIR IN EBEN HAEZAR MANADO CHRISTIAN HIGH SCHOOL}

\begin{abstract}
This study aims to describe the management of choir strategies in Kr. Eben Haezar Manado. This research is a qualitative research with descriptive method. Location of research in SMA Kr. Eben Haezar Manado, in 2018. Methods of data collection are observation, interviews and documentation. From the results of data analysis and interpretation, indications are obtained that: (1) The elements of strategy management that support the success of choir management are Man, Money, Method, Material, and Market. (2) Choir strategy management in SMA Kr. Eben Haezar Manado goes well. The strategy planning process is carried out by the management with guidance and input from the coaches and the coaches, and with supervision from the Eben Haezar Manado Foundation. From these findings, it is recommended that the management of Benzar Choir should make a written organizational structure in order to facilitate the affairs of the Benzar Choir data archive, and arrange the composition of the board by appointing coordinators so that they can help carry out better planned management of the strategy
\end{abstract}

Keywords: Management Strategy,, Choir 


\section{Pendahuluan}

Penampilan paduan suara asal Indonesia tidak bisa dipandang sebelah mata. Hampir setiap tahun Indonesia menyabet penghargaan tingkat Internasional, yang menempatkannya sejajar dengan Eropa. ${ }^{1}$ Perpaduan lagu daerah, aransemen yang bagus, dan koreografi yang atraktif menjadi ramuan yang menarik perhatian juri. Manado merupakan salah satu daerah di Indonesia yang banyak menyumbangkan kelompokkelompok paduan suara untuk kejuaraankejuaraan nasional maupun Internasional.

Manado adalah kota yang sedang berkembang dari berbagai sektor termasuk seni dan kebudayaan. Manado memiliki potensi yang terbilang unggul dari kotakota lainnya di Indonesia dalam hal menggali bakat bernyanyi, apakah itu individual maupun berkelompok seperti vocal group dan/atau paduan suara. Memiliki julukan sebagai 'sarang paduan suara' di Indonesia, Manado menjadi unik dan menarik. Semakin lengkap rasanya

\footnotetext{
${ }^{1}$ Media Online.

http://www.mediaindonesia.com/read/detail/83

187-pesona-paduan-suara-indonesia.

(Diakses tanggal 4 mei 2018).

${ }^{2}$ Media

Online.http://manadopostonline.com/read/201

7/03/10/Paduan-Suara-Jadi-Aset-Budaya-

Sulut/21077. (Diakses tanggal 4 Mei 2018).

${ }^{3}$ Media Online.

http://manado.tribunnews.com/2013/10/19/get semani-sakobar-choir-juara-di-kategorigospel-and-spiritual. (Diakses tanggal $4 \mathrm{Me}$ ${ }^{4}$ Media Online. 2018).

https://regional.kompas.com/read/2014/07/15/ $19455221 / 3$.Paduan.Suara.Sulawesi.Utara.Sa bet.Medali.Emas.dan.Perak.di.Latvia.( Diakses tanggal 4 Mei 2018).

${ }^{5}$ Media Online.

https://gorontalo.antaranews.com/berita/3736

6/paduan-suara-unima-manado-sukses-di-

london. (Diakses tanggal 4Mei 2018).
}

karena didukung penuh oleh pihak pemerintah dalam menjadikan seni paduan suara sebagai aset kota. ${ }^{2} \mathrm{Hal}$ itu terbukti dari setiap dukungan pemerintah kepada kelompok-kelompok paduan suara yang berprestasi hingga mampu mengharumkan nama Sulawesi Utara.

Beberapa kelompok paduan suara yang berprestasi di Nasional maupun Internasional antara lain adalahGetsemani Sakobar Choir, ${ }^{3}$ North Sulawesi Performing Art (NSPA), ${ }^{4}$ Manado State University Choir (MSUC), ${ }^{5}$ BRI Manado Choir, ${ }^{6}$ Gema Sangkakala Choir, ${ }^{7}$ Benzar choir (Eben Haezar High School Choir), ${ }^{8}$ Vox Angelica Choir, The Master Of Breakthrough, ${ }^{9}$ Nine's voice SMAN 9 Binsus Manado, ${ }^{10}$ dan masih banyak lagi.

Keberhasilan kelompok-kelompok paduan suara dalam meraih prestasi baik dalam dan luar negeri tentu tidaklah lepas dari faktor tata kelola yang baik di dalamnya. Sebab tanpa sistem manajerial yang baik terhadap setiap strategi atau rencana yang dimiliki, maka akan sangat

\footnotetext{
${ }^{6}$ Media Online.

http://manado.tribunnews.com/2017/07/23/brimanado-choir-bawa-pulang-dua-piala-daribali-international-choir-festival. (Diakses pada tanggal 4 Mei 2018).

${ }^{7}$ Media Online. http://indouslisting.com/article/gemasangkakala-choir-paduan-suara-konser-kelilingamerika.html. (Diakses tanggal 4 Mei 2018).

${ }^{8}$ Media online "manadopostonline.com" tanggal 17 Feb ${ }^{9}$ Media online. 2017. (Diakses tanggal 19 April 2018) http://manadopostonline.com/read/2016/03/17 /Spektakuler-The-1st-Manado-InternationalChoral-Expo/12985/1. (Diakses tanggal $4 \mathrm{Mei}$ 2018).

${ }^{10}$ Media onlone. https://news.detik.com/berita/2943596/kisahpaduan-suara-indonesia-yang-terdengarpaling-merdu-di-negeri-matador. (Diakses tanggal 4 Mei 2018).
} 
sulit bagi sebuah kelompok paduan suara untuk menjadi sukses. Hal ini sejalan dengan pendapat Karl-Edmund Prier yang mengatakan bahwa bahkan lebih dari $70 \%$ masalah paduan suara adalah masalah non-musiknya. ${ }^{11} \mathrm{Hal}$ ini juga didukung oleh pendapat Joel Ross dan Michael Kami dalam buku Fred R. David tentang Strategic Manajement: Concepts and Cases, yang mengatakan:

"Without a strategy, an organization is like a ship without a rudder, going around in circles. It's like a tramp; it has no place to go." ("Tanpa strategi, organisasi seperti kapal tanpa kemudi, berputar-putar. Seperti gelandangan; tidak memiliki tujuan. "). ${ }^{12}$

Salah satu kelompok paduan suara yang mampu menata sistem manajerial adalah Paduan Suara SMA Kristen Eben Haezar Manado atau yang lebih dikenal dengan Benzar Choir. Benzar Choir merupakan kelompok paduan suara berprestasi yang mampu menjaga eksistensi dalam berpaduan suara serta sangat kreatif dalam menampilkan repertoar paduan suaranya. Disamping banyaknya kegiatan sekolah yang dimiliki oleh para anggota Benzar Choir yang masih duduk di bangku kelas $\mathrm{X}, \mathrm{XI}$, dan XII, mereka mampu menjadikan Benzar Choir menjadi salah satu kelompok paduan

\footnotetext{
${ }^{11}$ Media online.

https://sasanamagnificat.wordpress.com/2008

/09/02/masalah-masalah-di-seputar-

pengelolaan-paduan-suara-anton-teguh/.

(Diakses tanggal 4 Mei 2018).
}

suara yang patut diperhitungkan di dunia paduan suara. Itu terbukti dari masuknya Benzar Choir dalam nominasi Kantar Choral Award 2017 dalam kategori paduan suara sekolah atau School Choir of The Year. $^{13}$

Benzar Choir merupakan salah satu dari ekstrakurikuler yang ada di SMA Kristen Eben Haezar Manado. Selain sebagai wadah penyaluran dan pengembangan bakat siswa, Benzar Choir juga menjadi wadah bagi siswa untuk belajar mengenai pengetahuan musik terutama teknik-teknik vocal dalam paduan suara. Benzar Choir memiliki visi dan misi sebagai pelayanan. Benzar Choir awalnya terbentuk dari beberapa siswa yang memiliki hobi bernyanyi dan membuat sebuah kelompok untuk tampil di acara natal SMA. Berkembang dari situ, kelompok ini akhirnya menjadi sebuah kelompok paduan suara yang sekarang telah memiliki banyak prestasi di bidang musik.

Keberhasilah Benzar Choir ditunjukkan melalui beberapa kategori yang berhasil dimenangkan, antara lain: Gold Champion Open Competition Kategori Gospel and Spiritual dalam Asia Pasific Choir Games 2013, Bali International Choir Festival 2013 Gold Medal kategori Gospel and Spiritual, Dies

\footnotetext{
${ }^{12}$ Fred R. David. Strategic Management: Concepts \& Cases, $13^{\text {th }}$ Edition.(New Jersey:Practice Hall, 2011). ha. 3

${ }^{13}$ Media online.

http://manadopostonline.com/read/2017/02/17 /Benzar-Choir-Nominasi-Kantar-ChoralAward/20556. (Diakses tanggal 4 Mei 2018).
} 
Natalis UNIMA (Lomba Paduan Suara Siswa Se-SULUT) juara 1 tahun 2014, Orientale Concentus VIII Gold Medal kategori Youth dan Best Dramaturgy Awards di Singapura tahun 2015, peringkat 5 kategori Youth di The $12^{\text {th }}$ Busan Choral festival and Competition di Korea Selatan tahun 2016. ${ }^{14}$ Dan yang terbaru mereka berhasil meraih Silver Medal level 9 kategori Youth di Sing n' Pray Kobe International Choir Festival and Competition 2018 di Jepang ${ }^{15}$ Dan masih banyak lagi.

Berdasarkan data-data di atas, maka muncullah pertanyaan bagaimana cara Benzar Choir mengelola kelompok paduan suara mereka sehingga mampu mendapatkan prestasi nasional maupun internasional. Mengingat bahwa Benzar Choir merupakan kelompok paduan suara sekolah yang tingkat turn over-nya anggotanya relatif cepat. Sehingga dapat dirumuskan persoalan pada penelitian ini adalah unsur manajemen strategi apa saja yang diterapkan dan bagaimana penerapannya.

Penelitian ini juga mengacu pada penelitian-peneltian sebelumnya seperti Manajemen Paduan Suara Consolatio Universitas Sumatera Utara, (Octaviana Tobing $^{16}$ ), dan Strategi Pembelajaran

\footnotetext{
${ }^{14}$ Media online "manadopostonline.com" tanggal 17 Feb 2017. (Diakses tanggal 19 April 2018).

${ }^{15}$ Media online. http://www.indonesiaosaka.org/berita/2018/01/29/sma-kristeneben-haezar-manado-tampil-memukau-diinternational-choir-competition-festival-2018/\#. (Diakses tanggal 4 Mei 2018).

${ }^{16}$ Octaviana Tobing. 2016. "Manajemen Paduan Suara

Consolatio Universitas Sumatera Utara".
}

Paduan Suara Mahasiswa Universitas Atma Jaya Yogyakarta, (Tetra Deputri Allopaa) $)^{17}$.

\section{Metode}

Penelitian ini menggunakan penelitian kualitatif dengan pendekatan ilmu manajemen organisasi. Penelitian ini dilakukan dilakukan pada bulan FebruariJuli 2019. Tempat penelitian di SMA Kristen Eben Haezar Manado, Jalan 14 Februari, Teling Atas, Manado. Sebagai narasumber penelitian ini adalah pelatih Benzar Choir yaitu Jacksen Pangemanan; pengurusangkatan VIII yaitu: Wedelyn Walelang sebagai ketua, Christova Somba sebagai wakil ketua, Grace Manopo sebagai sekertaris, Petra Lontoh sebagai wakil sekertaris, Amadea Sela sebagai bendahara, dan Jeremy Tanor sebagai wakil bendahara; dan anggota Benzar Choir yaitu Gisela Manengke dan Kurnia Patulak.

\section{Hasil dan Pembahasan \\ Benzar Choir}

Pembentukan kelompok paduan suara siswa Benzar Choir ini merupakan ide dari guru pembina seni musik di SMA

(http://digilib.unimed.ac.id/637/1/UNIMED-Article23814Oktaviana.pdf / Diunduh pada tanggal 23 April 2018).

\footnotetext{
17 Tetra Deputri Allopaa. "Strategi Pembelajaran Paduan Suara Mahasiswa Universitas Atma Jaya Yogyakarta". (Sripsi jurusan Pendidikan Seni Musik Fakultas Bahasa dan Seni, UNY. 2016).
} 
Kr. Eben Haezar, yaitu Bp. Yudha Kukihi, yang berinisiatif untuk mengumpulkan siswa-siswi kelas XI dan XII yang hobi bernyanyi, yang berasal dari sanggar, untuk mengisi acara tampil di acara natal SMA. ${ }^{18}$ Lambat laun, dari kelompok kecil tersebut terus berkembang menjadi kelompok besar paduan suara, dan pada pertengahan tahun 2009 kelompok paduan suara ini disebut Benzar Choir, yang beranggotakan siswa-siswi kelas $\mathrm{X}, \mathrm{XI}$ dan XII. ${ }^{19}$ Tujuan yang hingga kini masih dipegang teguh oleh para pengurus dan anggota Benzar Choir, yaitu melayani pujipujian di lingkungan sekolah dan juga di luar sekolah semakin diperkuat dengan semboyan mereka yaitu "Sing Glory to The Highest", ${ }^{20}$ yang berarti "Nyanyi syukur di tempat Yang Maha Tinggi”.

Berdasarkan sejarah terbentuknya, tujuan utama Benzar Choir adalah untuk melayani puji-pujian di lingkungan sekolah dan di luar sekolah. Bertolak dari tujuan utama itu maka Visi dan Misi Benzar Choiradalah melayani. ${ }^{21}$ Para pengurus

\footnotetext{
${ }^{18}$ hasil observasi tanggal 2 Mei 2018

19 dok. Foto cover album natal

${ }^{20}$ ibid
}

dan anggota dari Benzar Choir dibina dan diajarkan untuk memiliki hati melayani dan menomorduakan kemenangan dalam setiap kali perlombaan yang diikuti.

Tempat yang digunakan untuk latihan adalah di ruangan latihan choir yang bertempat di gedung baru Yayasan Eben Haezar Manado lantai 4, Jl. 14 Februari, Teling Atas. Sedangkan waktu latihan tiga kali seminggu, yaitu setiap hari senin, rabu, dan jumat; sepulang sekolah.

Kelompok paduan suara Benzar Choir berdiri dibawah pengawasan SMA Kr. Eben Haezar Manado dan Yayasan Eben Haezar Manado. Adapun para Guru pembina yang mengawasi jalannya Benzar Choir adalah bapak Yudha Kukihi (Guru seni musik SMA Kr. Eben Haezar Manado), bapak Yannade Pratasik (Guru seni musik dan wakil Kepala Sekolah SMA Kr. Eben Haezar), dan Ibu Alisa Eman (Guru Bahasa Inggris dan wakil Kepala Sekolah SMA Kr. Eben Haezar).

Pelatih Benzar Choir yang menjabat sekarang adalah Jacksen

\footnotetext{
${ }^{21}$ wawancara terhadap para pengurus tanggal 6 Juni 2018
} 
Pangemanan. la menjadi pelatih Benzar Choir sejak tahun 2013. Sebelum menjadi pelatih Benzar Choir, ia adalah seorang anggota Paduan Suara Gema Sangkakala dan pelatih Paduan Suara Remaja Gema Sangkakala. Selain menjadi pelatih di unit SMA, Jacksen Pangemanan juga berperan menjadi pelatih Benzar Choir unit SMP dan STIE. $^{22}$ Namun pada unit SMP, ia menempatkan salah satu teman yang dipercayai untuk melatih Choir SMP.

Jumlah anggota Benzar Choir seluruhnya \pm 50 orang siswa (termasuk pengurus), dan jumlah anggota aktif \pm 35 orang siswa (termasuk pengurus). ${ }^{23}$ Anggota Benzar Choir terdiri dari siswa kelas X, XI, dan XII SMA Kr. Eben Haezar Manado.

Pengurus Benzar Choir terdiri dari 6 orang, dengan susunan sebagai berikut: ketua (Wedelyn Walelang), wakil ketua (Christova Somba), sekertaris (Grace Manopo), wakil sekertaris (Petra Lontoh), bendahara (Amadea Sela) dan wakil bendahara (Jeremy Tanor). ${ }^{24}$ Para

\footnotetext{
22 wawancara pelatih tanggal 30 Juli 2018

23 observasi tanggal 2 Mei 2018

${ }^{24}$ Ibid
}

pengurus ini merupakan pengurus angkatan XIII.

Susunan organisasi Benzar Choir adalah sebagai berikut: ${ }^{25}$

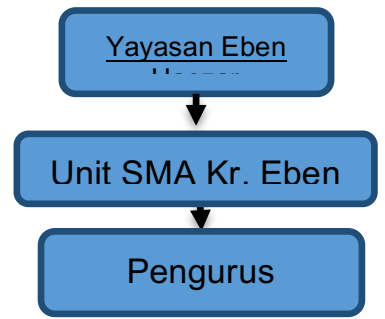

Tabel 1. Susunan Organisasi Benzar Choir

Unsur-unsur Manajemen Strategi Dalam Mendukung Keberhasilan Pengelolaan Paduan Suara Benzar Choir

Ada 5 unsur yang mendukung keberhasilan pengelolaan paduan suara, yaitu: manusia, uang, metode, bahan, dan pasar. ${ }^{26}$ Dalam prakteknya, unsur-unsur manajemen strategis yang terdapat di Benzar Choir memang mempengaruhi keberhasilan pengelolaan paduan suara Benzar Choir.

Unsur pertama yang paling penting adalah manusia atau anggota. Dalam prakteknya di kelompok paduan suara Benzar Choir, anggota sangat berperan dalam menjalankan strategi-strategi yang telah direncanakan oleh para pengurus. Para pengurus disini juga berperan untuk mengawasi para anggotanya. Selain para pengurus dan anggota, ada juga Guru Pembina dan Direktur Yayasan yang

\footnotetext{
${ }^{25}$ wawancara pelatih tanggal 30 Juli 2018

${ }^{26}$ M. Manullang. Dasar-dasar Manajemen. ha. 7.
} 
sesekali memantau perkembangan kegiatan yang dilakukan oleh Benzar Choir. Tanpa adanya anggota, manajemen strategi kelompok paduan suara Benzar Choir tidak akan berjalan dengan baik. Oleh sebab itu anggota adalah unsur yang penting dalam mendukung pengelolaan manajemen strategi paduan suara di Benzar Choir.

Unsur kedua yang tidak kalah penting adalah uang. Dalam kelompok Benzar Choir, para pengurus menetapkan uang iuran atau uang kas kepada setiap anggotanya sejumlah Rp. 4.000,-. Uang kas dibayarkan setiap hari latihan yaitu hari Senin, Rabu, dan Jumat. Uang yang telah terkumpul ini digunakan untuk jalannya administrasi organisasi, seperti: fotokopi partitur, membeli minuman untuk pelatih, dan sisanya digunakan untuk keperluan persiapan konser dan lomba atau event yang akan diikuti. Tanpa adanya uang kas ini, jalannya manajemen strategi di dalam oranisasi akan terhambat karena ketiadaan dana.

Unsur yang ketiga ialah metode atau strategi. Disinilah peran manajemen strategi dalam organisasi. Dalam kelompok paduan suara Benzar Choir unsur strategi ini sangat berpengaruh dalam keberhasilan mereka. Strategi ini digunakan untuk memperbaiki kelemahan dan memaksimalkan kekuatan yang dimiliki oleh kelompok paduan suara
Benzar Choir. Contoh pelaksanaannya dalam kelompok Benzar Choir ialah saat para pengurus dan pelatih mengambil keputusan strategi apa yang digunakan saat menghadapi tingkat pergantian anggota atau Turn-over yang tinggi. Benzar Choir menggunakan strategi mentoring dari pelatih dan anggotaanggota senior kepada anggota-anggota yang baru.

Unsur yang keempat ialah bahan atau Material. Dalam kelompok paduan suara Benzar Choir bahan-bahan yang digunakan ialah partitur untuk latihan. Sarana dan prasarana yang ada, yaitu ruangan dan keyboard untuk latihan juga termasuk unsur bahan yang mendukung keberhasilan pengelolaan kelompok paduan suara Benzar Choir.

Unsur yang trakhir yaitu pasar atau Market. Pasar sebuah kelompok paduan suara ialah masyarakat. Dalam kelompok paduan suara Benzar Choir, jemaat gereja termasuk dalam unsur yang terakhir ini.

\section{Manajemen Strategi Paduan Suara di SMA Kr. Eben Haezar Manado}

Fred David dalam bukunya yang berjudul Manajemen Strategi, berpendapat bahwa manajemen strategi memiliki 3 tahapan yang harus dilakukan, yaitu tahap perencanaan strategi, tahap implementasi strategi dan tahap evaluasi strategi. $^{27}$ Berikut adalah proses tahapan-tahapan

\footnotetext{
${ }^{27}$ Fred R. David. Strategic Management: Concepts \& Cases, $13^{\text {th }}$ Edition. ha. 6-7
} 
manajemen strategi paduan suara di SMA Kr. Eben Haezar Manado:

\section{Tahap Perencanaan}

Proses perencanaan manajemen strategi yang ada di kelompok paduan suara SMA Kr. Eben Haezar Manado atau yang sering disebut Benzar Choir, dilakukan oleh para pengurus Benzar Choir yang mendapat masukan atau arahan dari pelatih dan juga guru pembina, dan atas pengawasan dari Yayasan Eben Haezar Manado.

Dalam memutuskan sebuah keputusan, para pengurus harus meminta persetujuan dari pihak yayasan (Ketua Yayasan). Setelah Ketua Yayasan memberikan persetujuan barulah kemudian para pengurus dapat menjalankan perencanaan yang telah direncanakan. Para pengurus dan pelatih merencanakan strategi untuk proses latihan berdasarkan hasil evaluasi yang terlebih dahulu dilakukan sebelumnya. Mereka juga memikirkan bagaimana strategi untuk masalah-masalah yang dihadapi. Salah satu contohnya adalah dalam menghadapi tingkat Turn Over atau pergantian anggota yang relatif cepat dibanding dengan kelompok- kelompok paduan suara lain seperti sanggar atau lainnya.

Benzar Choir membuat strategi untuk mengatasi hal tersebut dengan mengandalkan kelebihan mereka, yaitu loyalitas pengurus, yang notabenenya

${ }^{28}$ Ibid. Ha. 6 adalah senior dalam kelompok paduan suara mereka.

Benzar Choir memilih sistem mentoring bagi para "junior" atau anggota baru agar dapat mengajarkan materi secara lebih detail dan mudah dipahami. Dampaknya pun cukup memuaskan. Para anggota baru lebih cepat belajar dan mengerti mengenai materi-materi yang ada dan mampu menerapkan setiap teknik menyanyi dengan baik. Pelatih juga mengambil peran dalam menangani masalah ini. Pelatih menjadi lebih fokus pada para anggota baru di bulan-bulan pertama terjadinya pergantian anggota dengan tujuan agar para anggota baru dapat terbina dengan baik.

Proses regenerasi pengurus yang dilakukan kelompok paduan suara Benzar Choir dilakukan oleh para pengurus yang sementara menjabat dan pelatih. Para pengurus akan memilih para anggota yang berkompeten untuk menggantikan posisi mereka. Proses ini sejalan dengan terori dari Fred David mengenai perumusan strategi yang menghasilkan pengalokasian sumber daya ${ }^{28}$ Penempatan sumber daya yang tepat pada posisi yang tepat akan menguntungkan kelompok paduan suara Benzar Choir dari segi manajemennya.

Berdasarkan tahapan manajemen strategi Fred R. David, salah satu tahapan dalam proses perencanaan adalah menentukan alternatif strategi. $^{29}$ Dalam menentukan alternatif strategi dibutuhkan

${ }^{29}$ Ibid. 
teknik analisis menggunakan matriks SWOT (Strengths, Weaksesses, Opportunities, dan Threats) dan kemudian dianalisa menggunakan strategi SO (Strengths-Opportunites), WO

(Weaknesses-Opportunities),

(Strengths-Threats), dan WT (Weaknesses-Threats).

Penggunaan matriks SWOT akan dibutuhkan data mengenai Strengths, Weaksesses, Opportunities, dan Threats yang telah dipaparkan pada subfokus Temuan Penelitian, dan dimasukkan kedalam bagan matriks SWOT sebagai berikut:

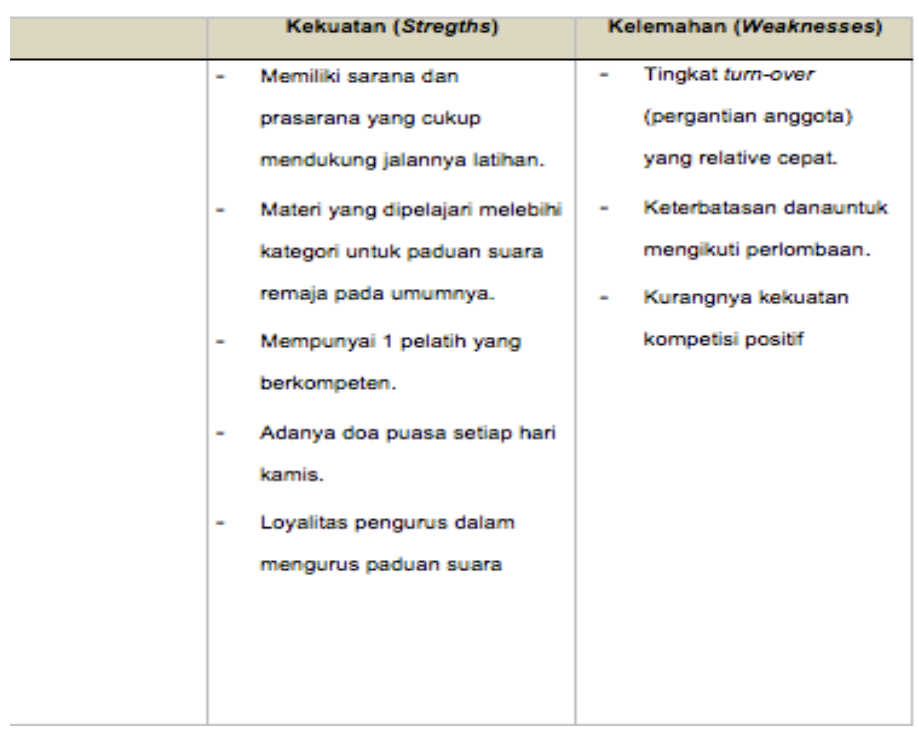

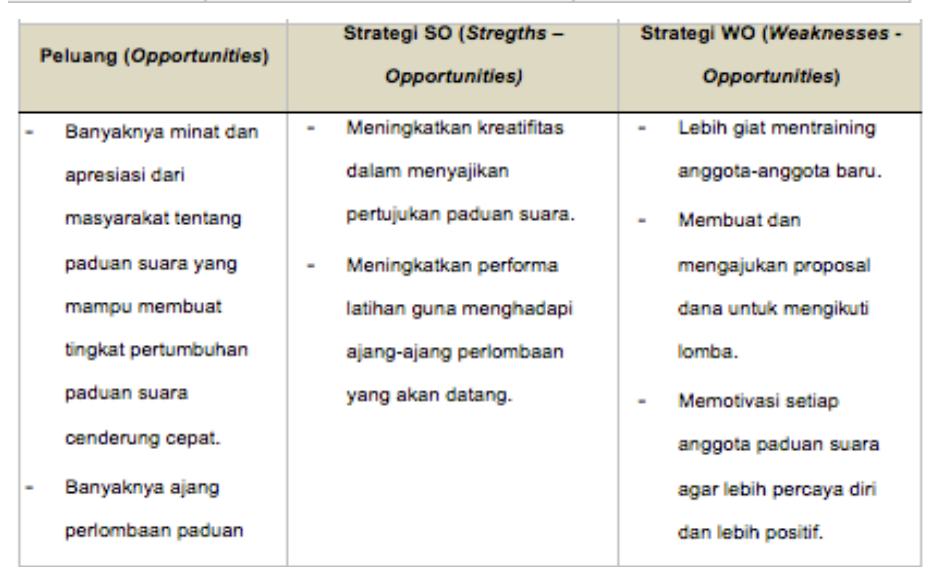

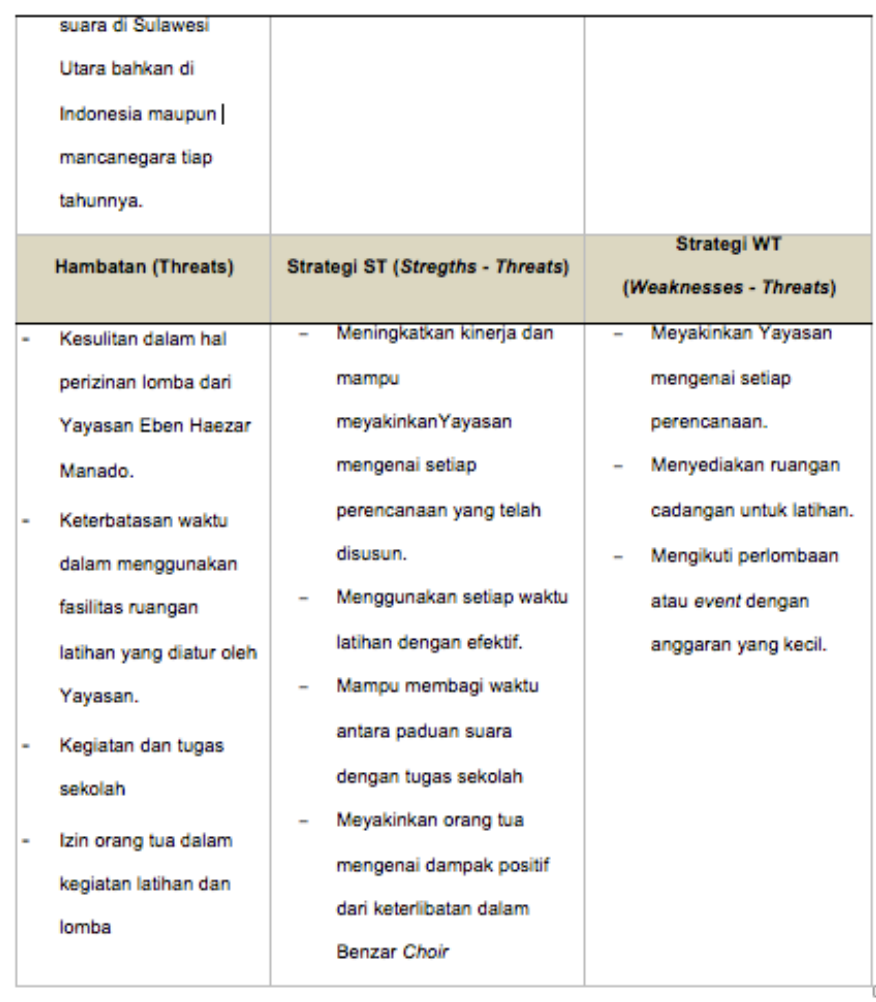

Tabel 2. Bagan Matriks SWOT

Berdasarkan temuan data yang dianalisa menggunakan strategi SO (Strengths-Opportunites), WO (Weaknesses-Opportunities), (Strengths-Threats), dan WT (Weaknesses-Threats) dari matriks SWOT, dihasilkan strategi-strategi sebagai berikut:

1. Strategi SO (StrengthsOpportunities):

$>$ Meningkatkan kreatifitas dalam menyajikan pertujukan paduan suara. Meningkatkan performa latihan guna menghadapi ajang-ajang perlombaan yang akan datang. 
Hasil dari strategi SO dalam poin yang pertama sejalan dengan teori dari Fred $\mathrm{R}$. David tentang proses perencanaan strategi yang menghasilkan keputusan untuk membuat suatu variasi. ${ }^{30}$ Variasi ini dibutuhkan untuk meningkatkan kualitas dan minat dari pasar atau penikmat pertunjukan kelompok paduan suara mereka.

2. Strategi WO (WeaknessesOpportunities):

$>$ Lebih giat mentraining anggota-anggota baru.

Membuat dan mengajukan proposal dana untuk mengikuti lomba.

Memotivasi setiap anggota paduan suara agar lebih percaya diri dan lebih positif.

3. Strategi ST (Strengths-Threats):

$>$ Meningkatkan kinerja dan mampu meyakinkan

Yayasan mengenai setiap perencanaan yang telah disusun.

Menggunakan setiap waktu latihan dengan efektif.

Mampu membagi waktu antara paduan suara dengan tugas sekolah Meyakinkan orang tua mengenai dampak positif

${ }^{30} \mathrm{lbid}$. dari keterlibatan dalam

Benzar Choir

4. Strategi WT (Weaknesses-

Threats):

Deyakinkan Yayasan mengenai setiap perencanaan.

Menyediakan ruangan cadangan untuk latihan.

Mengikuti perlombaan atau event dengan anggaran yang kecil.

2. Tahap Implementasi

Strategi-strategi yang telah didapatkan dari proses perencanaan kemudian diimplementasikan oleh pelatih, para pengurus, dan para anggota kelompok paduan suara Benzar Choir. Proses pengimplementasian strategi ini tidaklah lepas dari pengawasan guru pembina dan pihak dari yayasan.Para pengurus mampu menggerakkan para anggotanya untuk saling bekerja sama dalam menjalankan setiap strategi yang ada. Hal ini terbukti dari hasil wawancara dengan salah satu anggota Benzar Choir, Gisela Manengke, yang mengatakan bahwa para anggota juga ikut melaksanakan strategi yang telah mereka susun, salah satu contohnya ketika ada event lomba di luar negeri para anggota ikut mencari dana melalui penjualan makanan maupun menjalankan proposalproposal dana. ${ }^{31} \mathrm{Hal}$ ini terjadi karena para

\footnotetext{
${ }^{31}$ Wawancara Gisela Manengke tanggal 7 Juni 2018.
} 
pengurus terlebih dahulu memberikan teladan dalam pengimplementasian strategi melalui kinerja mereka, sehingga membuat para anggota akhirnya juga memilik hati untuk bekerja sama dalam mengimplementasikan strategi-strategi yang telah direncanakan. Hal ini sejalan dengan teori Fred R. David tentang hasil dari proses implementasi strategi, yaitu mampu mengembangkan budaya yang mendukung strategi yang telah dibuat. ${ }^{32}$ Mengembangkan budaya yang mendukung strategi ini diperlukan agar pengimplementasian strategi berjalan dengan merata dan efektif jika dilakukan secara bersama-sama.

Saat proses perencanaan dan pengimplementasian, kelompok paduan suara Benzar Choir tidak bisa lepas dari campur tangan Yayasan Eben Haezar karena kelompok paduan suara Benzar Choir berada di bawah naungan yayasan sehingga setiap kegiatan yang direncanakan harus atas sepengetahuan pihak yayasan (Ketua Yayasan).

Terdapat satu perbedaan dari teori yang dikemukakan oleh Fred R. David mengenai tahapan pengimplementasian strategi dengan pengimplementasian strategi yang dilakukan di kelompok paduan suara Benzar Choir, yaitu dalam teori Fred R. David mengemukakan salah satu tahapan implementasi strategi ialah mempersiapkan anggaran, namun dalam

\footnotetext{
${ }^{32}$ Fred R. David. Strategic Management:
} Concepts \& Cases, $13^{\text {th }}$ Edition. ha.7. pelaksanaan di kelompok paduan suara Benzar Choir, para pengurus mempersiapkan anggaran dana dalam proses perencanaan, yaitu saat membuat proposal untuk kegiatan yang akan diselenggarakan atau yang akan diikuti.

2. Tahap Evaluasi

Tahapan terakhir dalam manajemen strategis menurut Fred $\mathrm{R}$. David adalah proses evaluasi. ${ }^{33}$ Tahapan evaluasi dalam kelompok paduan suara Benzar Choir dilakukan setelah mengikuti sebuah perlombaan atau event tertentu. Dari hasil perlombaan yang diikuti, Benzar Choir melakukan evaluasi berdasarkan hasil catatan dari juri dan berdasarkan hasil rekaman video penampilan. Setelah mendapatkan hasil evaluasi, pelatih kemudian melakukan perencanaan kembali untuk mengatasi dan memperbaiki penampilan Benzar Choir kedepannya. Dalam hal evaluasi kinerja para pengurus, dilakukan rapat evaluasi setiap sebulan sekali untuk mengukur kinerja selama satu bulan dan mengambil tindakan korektif apabila terjadi kekurangan dalam kinerja selama satu bulan. Para pengurus menjalankan rapat bulanan tidak secara formal, namun secara santai kearah sharing mengenai kinerja para pengurus, apa yang sudah dilakukan dan apa yang harus diperbaiki atau ditingkatkan. Proses ini sejalan dengan tahapan evaluasi manajemen strategi dalam teori yang

${ }^{33} \mathrm{Ibid}$. 
diutarakan oleh Fred R. David yaitu mengukur kinerja dan mengambil tindakan korektif. ${ }^{34}$ Proses evaluasi dibutuhkan untuk mengetahui apakan strategi yang dilakukan sudah efektif untuk mendukung keberhasilan kelompok paduan suara Benzar Choir.

\section{Kesimpulan}

Dapat di simpulkan bahwa unsur-unsur manajemen strategi yang mendukung keberhasilan pengelolaan paduan suara di kelompok paduan suara Benzar Choir ialah Man, Money, Method, Material, dan Market. Unsur-unsur ini terbukti mampu mendukung keberhasilan pengelolaan paduan suara Benzar Choir. Unsur manusia (Man) disini ialah anggota dari Benzar Choir yang menjalankan manajemen strategi yang telah direncanakan. Unsur uang (Money) membantu kelancaran jalannya manajemen strategi dalam kelompok paduan suara Benzar Choir. Unsur strategi (Method) ialah strategi dalam menjalankan manajemen strategi agar berjalan dengan efisien dan efektif. Unsur bahan (Material) ialah sarana dan prasarana yangdapat mendukung keberhasilan kelompok paduan suara Benzar Choir. Dan yang terakhir ialah unsur pasar (Market) yang mempengaruhi perkembangan manajemen strategi Benzar Choir kedepannya. Unsur pasar memberikan umpan balik untuk kelompok paduan suara
Benzar Choir dalam meningkatkan performa kinerja dan performa pertunjukan.

Secara keseluruhan, Manajemen Strategi yang dijalankan oleh kelompok paduan suara Benzar Choir dilakukan dengan baik. Namun, sistem organisasinya masih belum jelas. Tidak ada arsip khusus yang menunjukkan sistem organisasi Benzar Choir. Proses perencanaan dilakukan oleh para pengurus dengan arahan dan masukan dari pelatih dan guru Pembina, dan oleh pengawasan dari pihak yayasan. Proses pengambilan keputusan dilakukan oleh Ketua Yayasan sebagai pemegang kekuasaan tertinggi, karena kelompok paduan suara Benzar Choir berada di bawah naungan Yayasan Eben Haezar.

Proses implementasi dilakukan oleh para pengurus, anggota dan juga pelatih oleh pengawasan guru Pembina dan pihak yayasan. Proses implementasi ini dilaksanakan bersama-sama untuk dapat melaksanakan strategi yang telah direncanakan dan mencapai tujuan yang telah disepakati. Proses evaluasi kelompok dilakukan setiap selesai mengikuti sebuah lomba atau event paduan suara. Para pengurus dan pelatih melakukan evaluasi secara terbuka, tidak hanya para pengurus dan pelatih, namun juga seluruh anggota Benzar Choir. Proses evaluasi dilakukan berdasarkan catatan dari juri dan berdasarkan rekaman video penampilan

${ }^{34}$ Ibid. 
Benzar Choir. Setelah melakukan evaluasi, maka para pengurus, terutama pelatih akan merencanakan kembali strategistrategi untuk mengatasi atau memperbaiki penampilan kedepannya. Sedangkan, proses evaluasi pengurus dilakukan setiap sebulan sekali dalam bentuk rapat bulanan. Para pengurus akan berdiskusi atau sharing mengenai kinerja yang telah dilakukan selama satu bulan. Setelah itu para pengurus akan mengambil tindakan memperbaiki kinerja yang buruk dan meningkatkan kinerja yang sudah baik.

\section{Kepustakaan}

Ansoff, Igor. Implanting Strategic Management. New Jersey: Practice Hall.1990.

Arikunto. Prosedur Penelitian Suatu Pendekatan Praktek. Jakarta: Rineka Cipta.1998.

Banoe, Pono. Kamus music. Yogyakarta: Kanisius.2003.

Basowi \& Suwandi. Memahami Penelitian Kualitatif. Jakarta: PT. Rineka Cipta. 2008.

Bungin, Burhan. Analisis Data Penelitian Kualitatif. Jakarta: PT. Raja Grafindo Persada.2013.

Choliq, Abdul. Pengantar Manajemen. Yogyakarta: Mitra Cendika. 2011.

David, Fred R.. Strategic Management: Concepts \& Cases $13^{\text {th }}$ Edition.New Jersey: Practice Hall.2011.

Handoko, Hani. Manajemen. Yogyakarta: BPFEE Yogyakarta. 1999.

Harahap, J.. Perkenalan Paduan Suara. Bandung: PT Remaja Rosdakarya.2005.

Hasibuan, Malayu S.P.. Manajemen: Dasar, Pengertian, dan Masalah. Edisi Revisi. Jakarta: PT. Bumi Aksara. 2001.
Jamalus dan A.T. Mahmud.. Buku Musik IV. Jakarta: Titik Terang. 1981.

Manullang, M.. Dasar-dasar Manajemen. Yogyakarta: Gadjah Mada Universitas Press.2002.

Nawawi, Handari dan M. Martini Handari. Instrumen Penelitian Bidang Sosial. Yogyakarta: Gajah Mada University Press.1992.

Nurhadiat, Dedi dan Untung Prayitno. Kerajinan Tangan dan Kesenian SD. Jakarta: Grasindo.2005.

Pusat Musik Liturgi. Menjadi Dirigen III. Yogyakarta: Pusat Musik Liturgi.2003.

Satori, Djam'an dan Aan Komariah. Metode Penelitian Kualitatif. Bandung: Alfabeta.2011.

Simanungkalit, N.. Teknik Vokal Paduan Suara. Jakarta: PT. Gramedia Pustaka Utama.2008.

Soeharto, M.. Membina Paduan Suara dan Grup Vokal. Jakarta: GraBedia.1979.

Sugiyono. Memahami Penelitian Kualitatif. Bandung: Alfabeta.2010. . Metode Penelitian Pendidikan Pendekatan Kuantitatif, Kualitatif, dan R\&D. Bandung: Alfabeta.2014.

Sutopo. Metodologi Penelitian Kualitatif (Dasar Teori dan Terapannya dalam Penelitian). Surakarta: UNS.2006.

Media online "manadopostonline.com" tanggal 17 Feb 2017. (Diakses tanggal 19 April 2018).

Media online.

http://manadopostonline.com/rea d/2016/03/17/Spektakuler-The1st-Manado-International-ChoralExpo/12985/1.(Diakses tanggal 4 Mei 2018).

Media Online. http://indouslisting.com/article/ge ma-sangkakala-choir-paduansuara-konser-kelilingamerika.html. (Diakses tanggal 4 Mei 2018). 